\title{
Prevalence and Associated Risk Factors for Obesity During Pregnancy Over Time
}

\author{
Zeitliche Untersuchung von Adipositasprävalenz und \\ assoziierten Risikofaktoren während der Schwangerschaft
}

Authors

Affiliations
T. N. Stüber ${ }^{1}$, E. C. Künzel ${ }^{1}$, U. Zollner ${ }^{1}$, M. Rehn ${ }^{1}$, A. Wöckel ${ }^{1}$, A. Hönig ${ }^{2}$

${ }^{1}$ Department of Obstetrics and Gynecology, University of Würzburg, Würzburg

2 Department of Obstetrics and Gynecology, St. Vincenz and Elisabeth Hospital, Mainz
Key words

obesity

pre-pregnancy BMI

- gestational weight gain

Schlüsselwörter

- Adipositas

- BMI

- Schwangerschaft

- Gewichtszunahme

\section{received 22.4.2015 \\ revised 23.6.2015 \\ accepted 15.7.2015}

Bibliography

DOI http://dx.doi.org/

10.1055/s-0035-1557868

Geburtsh Frauenheilk 2015; 75 :

923-928 @ Georg Thieme

Verlag KG Stuttgart · New York ISSN 0016-5751

\section{Correspondence}

Tanja Nadine Stüber

Department of Obstetrics

and Gynecology

University of Würzburg

Josef-Schneider-Straße 4

97080 Würzburg

Stueber_T@ukw.de

\section{Abstract \\ $\nabla$}

Objective: The increasing prevalence of obesity is having an impact on morbidity worldwide. Since young mature women are equally affected by the general increase in weight, the aim of the study was to evaluate the prevalence of obesity together with associated maternal risk factors, complications during pregnancy, and fetal outcomes in a local cohort for the years 2006 and 2011.

Study Design: Maternal and fetal records of women who delivered at the University of Würzburg, with a 5-year interval (2006 and 2011) between investigations, were retrospectively analyzed. Descriptive statistics included prevalence of obesity, maternal weight gain, as well as several complications during pregnancy and fetal characteristics. The association between maternal or fetal complications and extent of maternal obesity was analyzed.

Results: Our analysis included 2838 mothers with singleton pregnancies who delivered in 2006 ( $n=1293)$ or $2011(n=1545)$ in our department. We found that neither pre-pregnancy body mass index $\quad\left(23.77 \pm 4.85\right.$ vs. $24.09 \pm 5.10 \mathrm{~kg} / \mathrm{m}^{2}$, $\mathrm{p}=0.25)$ nor weight gain $(14.41 \pm 5.77$ vs. $14.78 \pm 5.65 \mathrm{~kg} ; \mathrm{p}=0.09$ ) increased significantly over time. But the majority of all overweight (71\%) or obese $(60.4 \%)$ mothers gained more weight than generally recommended. The prevalence of gestational diabetes, gestational hypertension, and preeclampsia increased significantly and was associated with high pre-pregnancy body mass index, as was delivery by cesarean section. However, obesity was not associated with prolonged pregnancy and did not seem to negatively affect fetal outcome.

Conclusion: There is a trend to increasing weight gain during pregnancy, and the majority of mothers, especially those with a high pre-pregnancy body mass index, exceeded the weight gain recommendations. Associated risk factors such as

\section{Zusammenfassung \\ $\nabla$}

Einleitung: Die steigende Prävalenz adipöser Menschen führt weltweit zu einer relevanten Morbidität, die auch junge Frauen im geschlechtsreifen Alter betrifft. Damit gerät der Themenkomplex Adipositas und assoziierte Komplikationen auch in Hinblick auf die Versorgung schwangerer Frauen in den Fokus. Das Ziel dieser Arbeit war es deshalb, die Adipositasprävalenz und hiermit assoziierte maternale und fetale Risikofaktoren zwischen 2006 und 2011 in einem lokalen Kollektiv zu untersuchen.

Material und Methoden: Die retrospektive Analyse umfasste alle maternalen und fetalen Daten von Patientinnen, die 2006 und 2011 an der Universitäts-Frauenklinik Würzburg von einem Einling entbunden wurden. Die deskriptive Statistik umfasste die Prävalenz von Adipositas und Gewichtszunahme, sowie maternale Risikofaktoren, Schwangerschaftskomplikationen und fetales Outcome. Weiterhin wurde eine Assoziation von maternalen und fetalen Komplikationen in Abhängigkeit vom Grad der Adipositas untersucht. Ergebnisse: Unsere Analyse umfasste $2838 \mathrm{~Pa}-$ tientinnen mit Einlingsgraviditäten, die in den Jahren $2006(\mathrm{n}=1293)$ und $2011(\mathrm{n}=1545)$ an der Universitätsklinik Würzburg entbunden haben. Es zeigte sich, dass weder der initiale BMI $\left(23,77 \pm 4,85\right.$ vs. $\left.24,09 \pm 5,10 \mathrm{~kg} / \mathrm{m}^{2}, \mathrm{p}=0,25\right)$ noch die Gewichtszunahme während der Schwangerschaft $(14,41 \pm 5,77$ vs. $14,78 \pm 5,65 \mathrm{~kg} ; \mathrm{p}=0,09)$ zwischen 2006 und 2011 signifikant anstiegen. Die Mehrheit der übergewichtigen (71\%) oder adipösen (60,4\%) Patientinnen überstieg die empfohlene Gewichtszunahme. Die Prävalenz von adipositasassoziierten Erkrankungen wie Gestationsdiabetes, präexistenter Hypertonus sowie Präeklampsie stiegen signifikant an und waren mit einem hohen initialen Body-Mass-Index assoziiert. Während Übergewichtigkeit nicht mit einer Terminüberschreitung assoziiert war, wur- 
gestational diabetes, hypertension, and delivery by cesarean section are increasing. den adipöse Patientinnen signifikant häufiger per Sectio caesarea entbunden. Das Geburtsgewicht war 2011 signifikant höher als 2006, wobei keine signifikanten Änderungen im fetalen Outcome dargestellt werden konnten.

Schlussfolgerung: Es gibt einen Trend zu vermehrter Gewichtszunahme während der Schwangerschaft. Assoziierte Risikofaktoren wie Gestationsdiabetes, Hypertonus und Kaiserschnittentbindung sind erhöht.

\section{Introduction}

Obesity has increased dramatically over the past 25 years and affects both developed and developing countries. It is well known that obesity is associated with a higher morbidity and is an important contributing factor for cardiovascular disease and type 2 diabetes worldwide. Obesity is usually described using the body mass index $\left(\mathrm{BMI}=\mathrm{kg} \mathrm{BW} /\right.$ height in $\mathrm{m}^{2}$ ). The WHO distinguishes between overweight (BMI $25-30 \mathrm{~kg} / \mathrm{m}^{2}$ ), obesity (BMI $>30 \mathrm{~kg} /$ $\mathrm{m}^{2}$ ) and extreme obesity (BMI $>40 \mathrm{~kg} / \mathrm{m}^{2}$ ). In $201234.9 \%$ of adults in the US were obese; the prevalence of obesity was higher among middle-aged adults than among younger persons or older adults [1]. The most recent data for Germany are from the national DEGS study which evaluated obesity in the German population between 2008 and 2011. Examination of the data showed that rates of overweight and obesity had increased compared to the data collected in 1998 and that younger men were particularly affected [2]. More than half of all pregnant women in the US are considered obese, with $8 \%$ considered extremely obese [3]. Obese pregnant women are likely to face several complications during pregnancy. They have a higher risk for gestational diabetes, hypertension and preeclampsia [4]. It is known that maternal obesity is associated with a higher risk of miscarriage and intrauterine death. Obesity is also associated with post-term pregnancy, a higher risk of cesarean section, and a higher risk of complications in emergency cesarean section [5].

In addition to these maternal risks, it is also known that maternal obesity is associated with several fetal risks. There is a higher risk of fetal growth abnormalities, intrauterine growth restriction and macrosomia, prematurity, anomalies, and adverse clinical outcomes. Obesity and nutritional status can have long-term effects on the energy balance in offspring and contribute to juvenile obesity and diabetes [6,7].

Recommendations for weight gain during singleton pregnancies are generally based on pre-pregnancy BMI. After reevaluating their guidelines in 2009, the Institute of Medicine (IOM) recommends a mean gestational weight gain (GWG) of around 11$15 \mathrm{~kg}$ for women with normal weight, $6-11 \mathrm{~kg}$ for overweight women and only 4-9 kg for obese women $[8,9]$.

The aim of this study was to analyze a local cohort of pregnant women with regard to obesity, weight gain in pregnancy, associated complications of pregnancy, and fetal outcome over time.

\section{Methods}

$\nabla$

This retrospective study included all women with singleton pregnancies who delivered in 2006 or 2011 in the Department of Obstetrics at the University of Würzburg. Mothers who had miscarriage, termination of pregnancy, or twin pregnancy, or whose data were incomplete were excluded from the study. Data acquisition was performed using the PERINAT program or patients' re- cords and included epidemiologic data of mother and child with a focus on obesity and obesity-associated complications during pregnancy. All data were analyzed using SPSS Statistics version 22. Descriptive statistics with average and standard deviation were used to analyze metric variables which were shown using quantile dot plots, while nominal and ordinal variables were analyzed using frequency tables. Statistical significance was assumed for $\mathrm{p}<0.05$.

\section{Maternal obesity}

All data on pre-pregnancy body weight, weight gain during pregnancy, and body weight at delivery were collected, and pre-pregnancy BMI was calculated. We did not calculate BMI at delivery since it does not offer a useful comparison between pregnant women. BMI was classified into normal weight $\left(25 \mathrm{~kg} / \mathrm{m}^{2}\right)$, overweight $\left(25-30 \mathrm{~kg} / \mathrm{m}^{2}\right)$ and obesity $\left(>30 \mathrm{~kg} / \mathrm{m}^{2}\right)$.

\section{Maternal complications}

We analyzed several maternal characteristics and complications. These included epidemiological data such as age, height, gravidity and parity. Commonly occurring pathologies such as gestational diabetes, divided into dietetically adjusted diabetes and insulin-dependent diabetes, were also included in the analysis. Gestosis complications such as pregnancy-induced hypertension (defined as RR >140/90 mmHg after the 20th week of gestation), preeclampsia or HELLP syndrome were analyzed descriptively.

We differentiated the mode of delivery into vaginal delivery and cesarean section (primary or secondary). Post-term delivery was also included in the analysis. Length of hospital stay postpartum was measured in days.

\section{Fetal outcome}

To evaluate fetal outcome we descriptively analyzed Apgar scores at 5 and 10 minutes, as well as arterial pH at delivery. Birth weight was expressed in grams.

\section{Association between obesity and complications during pregnancy}

We analyzed the association between pre-pregnancy BMI and the above epidemiologic data. Complications of pregnancy such as gestational diabetes, hypertension, preeclampsia, fetal macrosomia, post-term delivery, delivery by cesarean section, postpartum atonia, and impaired wound healing were evaluated with respect to their association with obesity.

\section{Results}

$\nabla$

We identified 2969 pregnant women who delivered in 2006 and 2011 in our department. After excluding multiple pregnancies ( $\mathrm{n}=131$ ) we analyzed 2838 pregnancies, 1545 in 2011 and 1293 in 2006. 


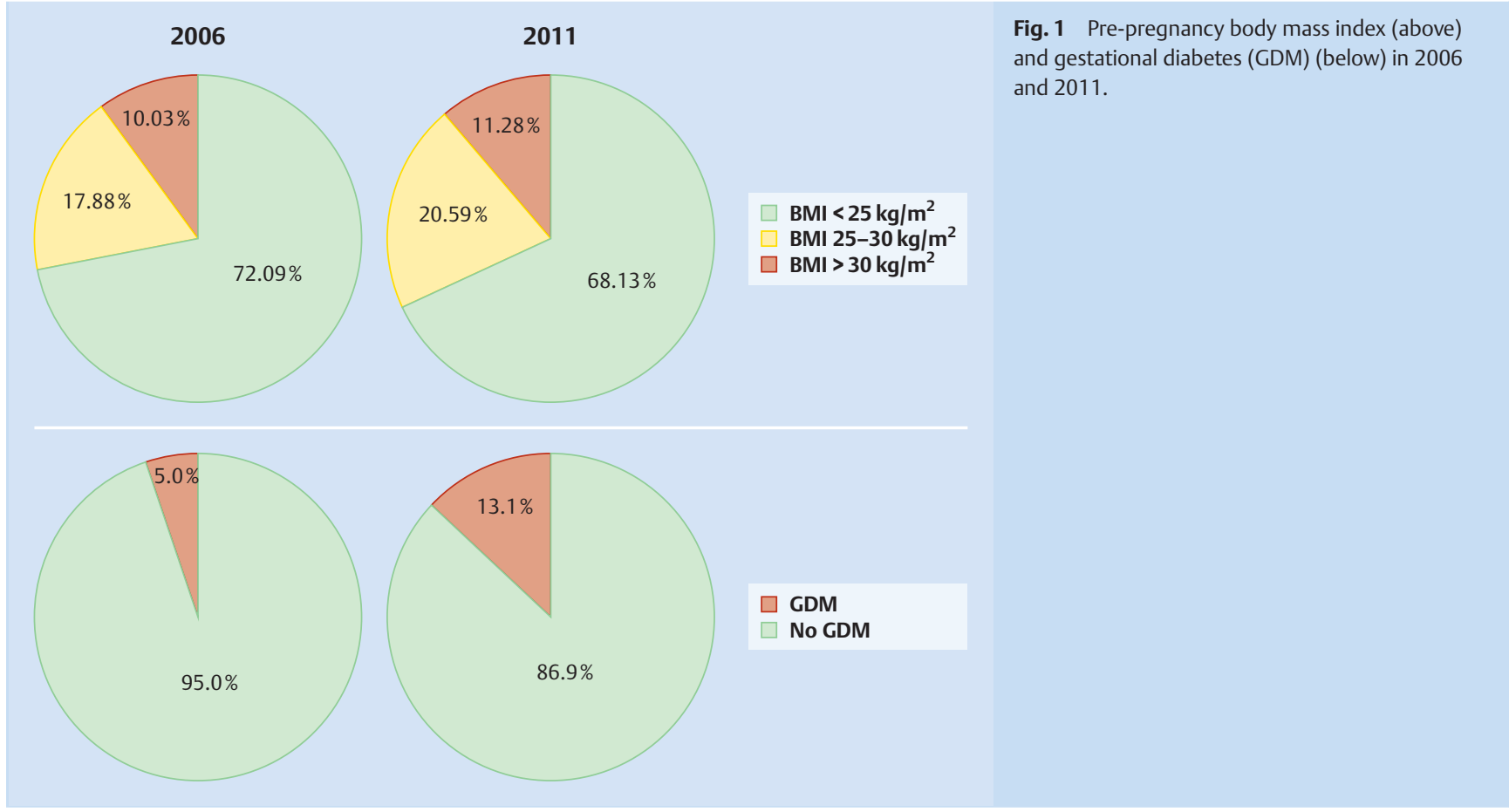

\section{Epidemiological data of the whole collective}

The mean age of all women included in the study was 30.91 $( \pm 5.11)$ years, with a mean height of $1.67( \pm 0.07) \mathrm{m}$ and a mean weight of $66.67( \pm 14.58) \mathrm{kg}$ at the start of pregnancy. This resulted in a mean pre-pregnancy BMI of $23.94( \pm 5) \mathrm{kg} / \mathrm{m}^{2} ; 19.4 \%$ of all women were overweight and $10.7 \%$ were obese. Overweight (BMI $25-30 \mathrm{~kg} / \mathrm{m}^{2}$ ) mothers were significantly older than normal weight or obese mothers $(p=0.01)$. The mean weight gain during pregnancy was calculated as $14.61( \pm 5.71) \mathrm{kg}$. A mean of $9.4 \%$ of mothers were diagnosed with gestational diabetes. The cesarean section rate was $31.7 \%$. Mean Apgar scores were 9.51 $( \pm 1.29)$ at 5 minutes and $9.72( \pm 1.15)$ at 10 minutes after delivery. Apgar scores 5 minutes after delivery were significantly lower for neonates delivered by primary $(p=0.04)$ or secondary $(p<0.01)$ cesarean section. Similarly, 10 minute Apgar scores were also lower for neonates delivered by primary $(\mathrm{p}=0.03)$ or secondary $(\mathrm{p}<0.01)$ cesarean section. Mean fetal arterial $\mathrm{pH}$ was $7.26( \pm 0.08)$ and mean birth weight was $3276.96( \pm 661.73) \mathrm{g}$. On average, patients stayed in hospital for $4.16( \pm 2.16)$ days.

\section{Comparison of 2006 with 2011}

A comparison of 2006 with 2011 showed no significant differences with regard to mean age (30.82 \pm 5.22 vs. $30.98 \pm 5.01$ years; $\mathrm{p}=0.4)$ or height $(1.67 \pm 0.06$ vs. $1.67 \pm 0.08 \mathrm{~m}$; $\mathrm{p}=0.5)$. There was no significant increase in pre-pregnancy BMI $\left(23.77 \pm 4.85\right.$ vs. $\left.24.085 \pm 5.10 \mathrm{~kg} / \mathrm{m}^{2}, \mathrm{p}=0.25\right)$ or gestational weight gain $(14.41 \pm 5.77 \mathrm{~kg}$ vs. $14.78 \pm 5.65 \mathrm{~kg}$; $\mathrm{p}=0.09)$ between 2006 and 2011. However, the percentage of overweight ( 17.9 vs. $20.6 \%$ ) or obese mothers increased (10 vs. $11.3 \%$ ) when 2006 was compared with 2011 ( Fig. 1). Moreover, the majority of mothers included in the study gained more weight during pregnancy than recommended by the IOM, both in 2006 and even more so in 2011. The rate of gestational diabetes was significantly increased in 2011 compared to 2006 (13.1 vs. 5.0\%; $\mathrm{p}<0.01$ ), with an increase in both dietetically managed (9.5 vs. $2.8 \%$; $<<0.01$ ) and insulin-dependent (3.6 vs. $2.2 \%$; $=0.04$ ) dia- betes ( $\bullet$ Fig. 1). Gestational diabetes was not significantly associated with fetal macrosomia in our study $(\mathrm{p}=0.07)$. Preexisting hypertension was diagnosed significantly more often in 2011 than in 2006 ( 1.8 vs. $0.7 ; p=0.02$ ). The prevalence of gestational hypertension ( 1.3 vs. $1.3 ; \mathrm{p}=1.0$ ) and preeclampsia (3.3 vs. 2.1; $\mathrm{p}=0.06$ ) did not increase between 2006 and 2011, while the prevalence of HELLP syndrome was significantly decreased in $2011(0.6 \%)$ compared to $2006(1.5 \%)(p=0.026)$. Post-term delivery occurred in $35.1 \%$ of cases in 2006 and in $41.2 \%$ in 2011 $(p<0.01)$. Delivery was by cesarean section in $32 \%$ of cases in 2006 and in $31.3 \%$ of cases in 2011 . Rates of shoulder dystocia were low in both years (2006: 1\% vs. 2011: $1.2 \%$ ) and did not differ significantly $(\mathrm{p}=0.68)$. Mean birth weight was $3247.38 \pm$ $694 \mathrm{~g}$ in 2006 and $3301.75 \pm 632.6 \mathrm{~g}$ in 2011, a significant increase over time $(\mathrm{p}=0.025)$. Mean arterial $\mathrm{pH}$ did not differ between 2006 and 2011 (7.26 \pm 0.76 vs. $7.26 \pm 0.08 ; p=0.92$ ), but Apgar scores at 5 and 10 min after delivery were significantly improved in 2011. Duration of postpartum stay in hospital was significantly lower in 2011 (4.31 \pm 7.48 vs. $4.02 \pm 1.86$ days; $\mathrm{p}>0.01$ ). Impaired wound healing was reported in 10 of 414 (2.4\%) cases in 2006 and in 8 of 483 (1.6\%) cases of cesarean section in 2011 ( $\mathrm{p}=0.48)$.

\section{Association between obesity}

and maternal/fetal complications

Of the women included in the study with a pre-pregnancy BMI $<25 \mathrm{~kg} / \mathrm{m}^{2}, 43.9 \%$ (2006) vs. $44.7 \%$ (2011) gained more than the recommended $15.8 \mathrm{~kg}$. Of the women with an initial BMI of 25$30 \mathrm{~kg} / \mathrm{m}^{2}, 68 \%$ (2006) vs. 73.8\% (2011) had a weight gain of more than the recommended $11 \mathrm{~kg}$, and $54.4 \%$ (2006) vs. 65.2 (2011) of mothers with an initial BMI of $>30 \mathrm{~kg} / \mathrm{m}^{2}$ gained more than $9 \mathrm{~kg}$, the maximum weight gain recommended by the IOM for obese mothers. Moreover, $41.7 \%$ of all patients with gestational diabetes had an initial BMI of $<25 \mathrm{~kg} / \mathrm{m}^{2}, 33.7 \%$ a BMI of $25-30 \mathrm{~kg} / \mathrm{m}^{2}$ and $24.6 \%$ a BMI of $>30 \mathrm{~kg} / \mathrm{m}^{2}$. In both years, 2006 and 2011, high BMI values were significantly associated with gestational diabe- 
Table 1 Comparison of demographic data of mother and fetus between 2006 and 2011. Data are presented as mean \pm standard or $\mathrm{n}(\%)$.

\begin{tabular}{|c|c|c|c|c|c|}
\hline Criteria & Total & $\mathrm{BMI}<25 \mathrm{~kg} / \mathrm{m}^{2}$ & BMI $25-30 \mathrm{~kg} / \mathrm{m}^{2}$ & $\mathrm{BMI}>30 \mathrm{~kg} / \mathrm{m}^{2}$ & p-value \\
\hline \multirow{2}{*}{$\begin{array}{l}\text { Gestational weight gain exceeding } \\
\text { IOM recommendations }\end{array}$} & $1327(51.3)$ & $800(44.3)$ & $359(71.7)$ & $168(60.4)$ & \\
\hline & $\mathrm{n}=2585$ & $\mathrm{n}=1806$ & $n=501$ & $n=278$ & \\
\hline \multirow[t]{2}{*}{ Gestational diabetes } & $264(9.4)$ & $110(5.6)$ & $89(16.2)$ & $65(21.3)$ & $<0.01$ \\
\hline & $\mathrm{n}=2810$ & $n=1957$ & $\mathrm{n}=548$ & $\mathrm{n}=305$ & \\
\hline \multirow[t]{2}{*}{ Pre-pregnancy hypertension } & $37(2.9)$ & $12(1.3)$ & $8(3.5)$ & $17(12.6)$ & $<0.01$ \\
\hline & $n=1263$ & 900 & 228 & 135 & \\
\hline \multirow[t]{2}{*}{ Gestational hypertension } & $36(1.3)$ & $11(0.6)$ & $13(2.5)$ & $12(4.1)$ & $<0.01$ \\
\hline & $\mathrm{n}=2717$ & $\mathrm{n}=1900$ & $n=526$ & $\mathrm{n}=291$ & \\
\hline \multirow[t]{2}{*}{ Preeclampsia } & $73(2.7)$ & $36(1.9)$ & $16(3.0)$ & $21(7.2)$ & $<0.01$ \\
\hline & $n=2717$ & 1900 & 526 & 291 & \\
\hline \multirow[t]{2}{*}{ Post-term delivery } & $1049(3.9)$ & $733(38.6)$ & $201(38.2)$ & $115(39.5)$ & 0.85 \\
\hline & $n=2717$ & $\mathrm{n}=1900$ & $\mathrm{n}=526$ & $\mathrm{n}=291$ & \\
\hline \multirow[t]{2}{*}{ Fetal macrosomia } & $31(1.1)$ & $17(0.9)$ & $7(1.3)$ & $7(2.4)$ & 0.25 \\
\hline & $n=2715$ & $n=1899$ & $n=526$ & $n=290$ & \\
\hline \multirow[t]{2}{*}{ Shoulder dystocia } & $31(1.15)$ & $23(1.2 \%)$ & $5(0.9 \%)$ & $3(1 \%)$ & 0.89 \\
\hline & $n=2717$ & $\mathrm{n}=1900$ & $n=526$ & $n=291$ & \\
\hline \multirow[t]{2}{*}{ Cesarean section (CS) } & $706(26.0)$ & $439(23.1)$ & $158(30)$ & $109(37.5)$ & 0.01 \\
\hline & $\mathrm{n}=2716$ & $\mathrm{n}=1899$ & $n=526$ & $n=291$ & \\
\hline \multirow[t]{2}{*}{ - elective CS } & $345(12.7)$ & $205(10.8)$ & $81(15.4)$ & $59(20.3)$ & $<0.01$ \\
\hline & $n=2716$ & $\mathrm{n}=1899$ & $n=526$ & $n=291$ & \\
\hline \multirow[t]{2}{*}{ - secondary CS } & $362(13.3)$ & $235(12.4)$ & $77(14.6)$ & $50(17.2)$ & $<0.01$ \\
\hline & $n=2717$ & $\mathrm{n}=1900$ & $\mathrm{n}=526$ & $\mathrm{n}=291$ & \\
\hline \multirow[t]{2}{*}{ Postpartum atonia } & $145(5.3)$ & $106(5.6)$ & $28(5.3)$ & $11(3.8)$ & 0.25 \\
\hline & $n=2716$ & $n=1899$ & $n=526$ & $\mathrm{n}=291$ & \\
\hline \multirow[t]{2}{*}{ Impaired wound healing } & $19(0.7)$ & $13(0.7)$ & $4(0.8)$ & $2(0.7)$ & 0.98 \\
\hline & $n=2717$ & $\mathrm{n}=1900$ & $n=526$ & $n=291$ & \\
\hline
\end{tabular}

Table 2 Single-factor variance analysis for the association between maternal or fetal characteristics and pre-pregnancy BMI. Data are presented as mean \pm standard.

\begin{tabular}{|c|c|c|c|c|}
\hline Criteria & $\mathrm{BMI}<25 \mathrm{~kg} / \mathrm{m}^{2}$ & BMI $25-30 \mathrm{~kg} / \mathrm{m}^{2}$ & $\mathrm{BMI}>30 \mathrm{~kg} / \mathrm{m}^{2}$ & p-value \\
\hline \multirow[t]{2}{*}{ Age (years) } & $30.8 \pm 5.0$ & $31.6 \pm 5.2$ & $30.9 \pm 5.1$ & 0.01 \\
\hline & $n=1900$ & $n=526$ & $n=291$ & \\
\hline \multirow{2}{*}{ Body weight $(\mathrm{kg})$} & $59.5 \pm 6.8$ & $75.5 \pm 6.6$ & $97.2 \pm 14.3$ & $<0.01$ \\
\hline & $n=1900$ & $n=526$ & $n=291$ & \\
\hline \multirow[t]{2}{*}{ Gestational weight gain $(\mathrm{kg})$} & $15.2 \pm 5.12$ & $14.41 \pm 5.83$ & $11.5 \pm 7.8$ & $<0.01$ \\
\hline & $n=1806$ & $n=501$ & $n=278$ & \\
\hline \multirow[t]{2}{*}{ Apgar score 5 min } & $9.6 \pm 1.3$ & $9.6 \pm 1.2$ & $9.27 \pm 1.5$ & $<0.01$ \\
\hline & $n=1899$ & $n=525$ & $\mathrm{n}=289$ & \\
\hline \multirow[t]{2}{*}{ Apgar score $10 \mathrm{~min}$} & $9.7 \pm 1.1$ & $9.8 \pm 1.0$ & $9.6 \pm 1.3$ & 0.12 \\
\hline & $n=1899$ & $n=525$ & $n=288$ & \\
\hline \multirow[t]{2}{*}{ Fetal arterial $\mathrm{pH}$} & $7.26 \pm 0.1$ & $7.26 \pm 0.1$ & $7.27 \pm 0.1$ & 0.3 \\
\hline & $\mathrm{n}=1841$ & $\mathrm{n}=515$ & $n=279$ & \\
\hline \multirow[t]{2}{*}{ Birth weight $(\mathrm{g})$} & $3260.4 \pm 620.1$ & $3372.6 \pm 637.8$ & $3277.7 \pm 839.3$ & $<0.01$ \\
\hline & $\mathrm{n}=1899$ & $n=526$ & $n=290$ & \\
\hline \multirow[t]{2}{*}{ Postpartum stay in hospital (days) } & $4.1 \pm 2.0$ & $4.2 \pm 2.0$ & $4.4 \pm 3.2$ & 0.13 \\
\hline & $n=1896$ & $n=525$ & $n=291$ & \\
\hline
\end{tabular}

tes $(\mathrm{p}=0.01$ and $\mathrm{p}=0.02)$. Patients with a pre-pregnancy BMI of $>30 \mathrm{~kg} / \mathrm{m}^{2}$ presented significantly more often with pre-pregnancy hypertension than patients with lower BMI values (68/ $124 ; 54.8 \%$ vs. $4 / 1112 ; 0.4 \% \mathrm{p}<0.01$ and 2011 : $11 / 167 ; 6.6 \%$ vs. $16 / 13141.2 \% \mathrm{p}<0.01$ ). Preeclampsia, gestational hypertension and preexisting hypertension were associated with overweight or obesity $(\mathrm{p}<0.01)$. High pre-pregnancy BMI was not associated with post-term delivery in either 2006 or $2011(\mathrm{p}=0.05$ and $\mathrm{p}=0.07$ ). In both years, 2006 and 2011, high pre-pregnancy-BMI was significantly associated with delivery by cesarean section
(2006: $24.1 \% / 31.2 \% / 41.9 \% \mathrm{p}<0.01$ and $2011: 22.2 \% / 29.1 \% / 34 \%$; $\mathrm{p}<0.01$ ). It is becoming apparent that both elective and secondary cesarean section rates are associated with obesity, and that rates increase with higher pre-pregnancy BMI $(p<0.01)$. There was no significant association between shoulder dystocia and high pre-pregnancy BMI $(p=0.89)$. High pre-pregnancy BMI was not found to be significantly associated with higher rates of perineal $(p=0.69)$ or vaginal lacerations $(p=3.2)$. However, infants of overweight mothers had significantly higher birth weights than those born to normal weight mothers $(\mathrm{p}<0.01)$. When pre-preg- 
nancy BMI and fetal outcome were compared for all women, children of obese mothers had significantly worse Apgar scores at 5 minutes after delivery than children of normal weight or overweight mothers $(\mathrm{p}<0.01)$. However, Apgar scores at 10 minutes post delivery did not significantly differ between pre-pregnancy BMI groups $(\mathrm{p}=0.12)$. Fetal arterial $\mathrm{pH}$ was also not significantly different between BMI groups $(\mathrm{p}=0.3)$. There was no significant correlation between postpartum atonia and increased pre-pregnancy BMI in both years, and there was no significant correlation between obesity and duration of hospital stay $(p=0.13)$. Wound healing after cesarean section was not associated with increased pre-pregnancy BMI ( $\mathrm{p}=0.98)(\bullet$ Tables 1 and 2$)$.

\section{Discussion}

$\nabla$

Given the dramatic increase in the prevalence of obesity worldwide, it is hardly surprising that women of fertile age are also becoming more obese. Since overweight and obesity in pregnancy are associated with various maternal und fetal risks, the IOM has issued recommendations on the weight gain during pregnancy based on pre-pregnancy BMI. These recommendations are often exceeded. In spite of all efforts to reduce obesity and minimize risk factors, obesity still plays a crucial role in prenatal, perinatal, and postnatal care. This study showed that weight gain in pregnancy tended to increase in a local single-center collective observed at an interval of 5 years. The risks and complications associated with increased maternal weight are described.

Analysis showed that there was no significant increase in prepregnancy BMI or weight gain during pregnancy when 2006 was compared with 2011. This data is consistent with the findings of Mensink et al. who stated that the prevalence of overweight in Germany has not changed in the past 15 years, although the prevalence of obesity has particularly increased in men [2]. Ogden et al. confirmed that there was no significant increase in obesity in the US in young people or adults when they compared the period 2003-2004 with 2011-2012 [10]. However, our analysis showed a trend to increased weight gain during pregnancy when comparing 2006 with 2011. The observation period may have been too short to recognize other significant differences. However, even if all overweight or obese mothers of the whole collective gained significantly less weight than normal weight mothers, the recommended weight gain of the IOM was often exceeded. Especially in overweight or obese mothers there were significantly increased rates of pregnancy-associated complications. Both dietetically managed and insulin-dependent gestational diabetes increased significantly over time, and mothers who developed gestational diabetes were more often overweight or obese, a finding which is in line with several publications [11, 12 ]. But this increase in gestational diabetes might also be a consequence of the increasing awareness of high numbers of previously unreported cases of gestational diabetes. From this, it follows that international recommendations for general screening are widely complied with, although screening was not covered by health insurance companies in Germany at the time. Analysis showed that overweight and obesity were not significantly associated with fetal macrosomia when compared to mothers with normal weight. It could be postulated that this is due to regular ultrasound monitoring of the fetus and improved metabolic control during pregnancy, since several publications have shown that ultrasound-guided monitoring and adjusted insulin treatment improves birth weight distribution $[13,14]$. Obesity is gen- erally known to be a risk factor for cardiovascular disease. In our analysis overweight and obese mothers presented significantly more often with pre-pregnancy hypertension, and the prevalence of pre-pregnancy hypertension was significantly higher in 2011. Pregnancy-induced hypertension and preeclampsia were also associated with higher BMI, but the prevalence did not increase over time, which is in line with the literature $[15,16]$. In this analysis, women with high pre-pregnancy BMI did not give birth after 40 weeks of gestation more often than normal weight women did, but they delivered significantly more often by cesarean section. It is known that obese women are at higher risk of delivery by cesarean section [17]. Fetal birth weight increased significantly between 2006 and 2011. This might be due to maternal obesity, in line with the findings reported in the literature [18], and could lead to higher rates of adverse outcomes in offspring [19]. Interestingly, newborns of overweight mothers were significantly heavier than those of obese or normal weight mothers. Apgar scores at 10 minutes and fetal arterial pH did not differ significantly when the various pre-pregnancy BMI categories were compared. Contrary to our expectations, impaired wound healing after cesarean section only occurred in a few cases and was not significantly associated with high pre-pregnancy BMI. It is possible that this result is misleading and could be due to missing records, since patients may have been treated by their own gynecologist.

Our study found that the majority of overweight and obese women presented with associated complications and exceeded weight gain recommendations that were developed to optimize fetal outcomes and prevent excessive fetal growth and maternal risks. The question therefore arises whether the current information and education of mothers about risk factors and preventive behavior is sufficient. Ronnberg et al. showed that a low-cost intervention program was able to reduce gestational weight gain significantly and that fewer women exceeded IOM recommendations after counseling [20]. In several meta-analyses, dietary intervention was able to reduce gestational weight gain $[21,22]$ and associated risks such as preeclampsia [23], even though it did not alter birth weight [21]. However, a Cochrane analysis of 28 studies showed that there is not enough evidence to recommend prophylactic intervention to prevent excessive gestational weight gain, due to methodological limitations of the investigated studies [24]. More randomized controlled studies are required.

This study is limited by its retrospective design and lacks the advantages of a big prospective randomized controlled multicenter study. Nevertheless, the goal of the study was to analyze a local cohort over time and characterize the prevalence of obesity and associated complications during pregnancy.

In summary, we present a single-center retrospective analysis of the prevalence and associated complications of obesity during pregnancy. We observed that there is a trend to increased gestational weight gain, although pre-pregnancy BMI did not increase significantly over the 5-year period. It was found that the majority of overweight or obese mothers gained more weight than recommended by the IOM. They presented significantly more often with pre-pregnancy or pregnancy-induced hypertension and showed a higher prevalence of gestational diabetes. Even though there is still disagreement about the benefits of early intervention, offering women of fertile age and pregnant women extensive early counseling about the risks associated with obesity during pregnancy should be considered. 


\section{Conflict of Interest}

$\nabla$

None.

\section{References}

1 Ogden CL, Carroll MD, Kit BK et al. Prevalence of obesity among adults: United States, 2011-2012. NCHS Data Brief 2013; (131): 1-8

2 Mensink GB, Schienkiewitz A, Haftenberger $M$ et al. [Overweight and obesity in Germany: results of the German Health Interview and Examination Survey for Adults (DEGS1)]. Bundesgesundheitsblatt, Gesundheitsforschung, Gesundheitsschutz 2013; 56: 786-794

3 Flegal KM, Carroll MD, Kit BK et al. Prevalence of obesity and trends in the distribution of body mass index among US adults, 1999-2010. JAMA 2012; 307: 491-497

4 Cedergren MI. Maternal morbid obesity and the risk of adverse pregnancy outcome. Obstet Gynecol 2004; 103: 219-224

5 American College of Obstetricians and Gynecologists. ACOG Committee opinion no. 549: obesity in pregnancy. Obstet Gynecol 2013; 121: 213-217

6 Sullivan EL, Grove KL. Metabolic imprinting in obesity. Forum Nutr 2010; 63: 186-194

7 Oken E, Rifas-Shiman SL, Field AE et al. Maternal gestational weight gain and offspring weight in adolescence. Obstet Gynecol 2008; 112: 9991006

8 Rasmussen KM, Catalano PM, Yaktine AL. New guidelines for weight gain during pregnancy: what obstetrician/gynecologists should know. Curr Opin Obstet Gynecol 2009; 21: 521-526

9 Rasmussen KM, Yaktine AL, eds. Weight Gain during Pregnancy: reexamining the Guidelines. Washington (DC): The National Academies Collection, Reports funded by National Institutes of Health; 2009

10 Ogden CL, Carroll MD, Kit BK et al. Prevalence of childhood and adult obesity in the United States, 2011-2012. JAMA 2014; 311: 806-814

11 Chu SY, Callaghan WM, Kim SY et al. Maternal obesity and risk of gestational diabetes mellitus. Diabetes Care 2007; 30: 2070-2076

12 Baeten JM, Bukusi EA, Lambe M. Pregnancy complications and outcomes among overweight and obese nulliparous women. Am J Public Health 2001; 91: 436-440
13 Balsells M, Garcia-Patterson A, Gich I et al. Ultrasound-guided compared to conventional treatment in gestational diabetes leads to improved birthweight but more insulin treatment: systematic review and meta-analysis. Acta Obstet Gynecol Scand 2014; 93: 144-151

14 Langer 0 . Glycemic targets for the optimal treatment of GDM. Clin Obstet Gynecol 2013; 56: 788-802

15 Jeyabalan A. Epidemiology of preeclampsia: impact of obesity. Nutr Rev 2013; 71 (Suppl. 1): S18-S25

16 Salihu HM, De La Cruz C, Rahman S et al. Does maternal obesity cause preeclampsia? A systematic review of the evidence. Minerva Ginecol 2012; 64: 259-280

17 Crane SS, Wojtowycz MA, Dye TD et al. Association between pre-pregnancy obesity and the risk of cesarean delivery. Obstet Gynecol 1997; 89: $213-216$

$18 \mathrm{Yu} \mathrm{Z,} \mathrm{Han} \mathrm{S,} \mathrm{Zhu} \mathrm{J} \mathrm{et} \mathrm{al.} \mathrm{Pre-pregnancy} \mathrm{body} \mathrm{mass} \mathrm{index} \mathrm{in} \mathrm{relation} \mathrm{to}$ infant birth weight and offspring overweight/obesity: a systematic review and meta-analysis. PloS one 2013; 8: e61627

19 Palatianou ME, Simos YV, Andronikou SK et al. Long-term metabolic effects of high birth weight: a critical review of the literature. Horm Metab Res 2014; 46: 911-920

20 Ronnberg AK, Ostlund I, Fadl H et al. Intervention during pregnancy to reduce excessive gestational weight gain-a randomised controlled trial. BJOG 2015; 122: 537-544

21 Quinlivan JA, Julania S, Lam L. Antenatal dietary interventions in obese pregnant women to restrict gestational weight gain to Institute of Medicine recommendations: a meta-analysis. Obstet Gynecol 2011; 118: $1395-1401$

22 Streuling I, Beyerlein A, Rosenfeld E et al. Physical activity and gestational weight gain: a meta-analysis of intervention trials. BJOG 2011; 118 : 278-284

23 Allen R, Rogozinska E, Sivarajasingam P et al. Effect of diet- and lifestylebased metabolic risk-modifying interventions on preeclampsia: a meta-analysis. Acta Obstet Gynecol Scand 2014; 93: 973-985

24 Muktabhant B, Lumbiganon P, Ngamjarus C et al. Interventions for preventing excessive weight gain during pregnancy. Cochrane Database Syst Rev 2012; 4: CD007145 